\title{
Induction of IL-17A precedes development of airway hyperresponsiveness during diet-induced obesity and correlates with complement factor D
}

\author{
Joel A. Mathews*, Allison P. Wurmbrand, Luiza Ribeiro, Felippe Lazar Neto and Stephanie A. Shore
}

Molecular and Integrative Physiological Sciences Program, Department of Environmental Health, Harvard School of Public Health, Boston, MA, USA

\section{Edited by:}

Giamila Fantuzzi, University of Illinois

at Chicago, USA

Reviewed by:

Michael Kracht,

Justus-Liebig-University Giessen,

Germany

Bo Shen, University of Illinois at

Chicago, USA

*Correspondence:

Joel A. Mathews, Molecular and Integrative Physiological Sciences

Program, Department of

Environmental Health, Harvard School

of Public Health, 665 Huntington

Avenue, Boston, MA 02115, USA

e-mail: jmathews@hsph.harvard.edu
Obesity is a risk factor for the development of asthma. Obese mice exhibit innate airway hyperresponsiveness (AHR), a characteristic feature of asthma, and IL-17A is required for development of AHR in obese mice. The purpose of this study was to examine the temporal association between the onset of AHR and changes in IL-17A during the development of obesity by high-fat feeding in mice. At weaning, C57BL/6J mice were placed either on mouse chow or on a high-fat diet (HFD) and examined 9, 12, 15, 18, or 24 weeks later. Airway responsiveness to aerosolized methacholine (assessed via the forced oscillation technique) was greater in mice fed HFD versus chow for 24 weeks but not at earlier time points. Bronchoalveolar lavage and serum IL-17A were not affected by either the type or duration of diet, but increased pulmonary IL 17a mRNA abundance was observed in HFD versus chow fed mice after both 18 and 24 weeks. Flow cytometry also confirmed an increase in IL-17A $\gamma \delta \mathrm{T}$ cells and IL-17A+ ${ }^{+} \mathrm{CD} 4^{+} \mathrm{T}$ (Th17) cells in lungs of HFD versus chow fed mice. Pulmonary expression of $C f d$ (complement factor $\mathrm{D}$, adipsin), a gene whose expression can be reduced by IL-17A, decreased after both 18 and 24 weeks in HFD versus chow fed mice. Furthermore, pulmonary $C f d$ mRNA abundance correlated with elevations in pulmonary II17a mRNA expression and with AHR. Serum levels of TNF $\alpha$, MIP-1 $\alpha$, and MIP-1 $\beta$, and classical markers of systemic inflammation of obesity were significantly greater in HFD than chow fed mice after 24 weeks, but not earlier. In conclusion, our data indicate that pulmonary rather than systemic IL-17A is important for obesity-related AHR and suggest that changes in pulmonary $C f d$ expression contribute to these effects of IL-17A. Further, the observation that increases in I/17a preceded the development of AHR by several weeks suggests that IL-17A interacts with other factors to promote AHR. The observation that the onset of the systemic inflammation of obesity coincided temporally with the development of AHR suggest that systemic inflammation may be one of these factors.

Keywords: complement factor D, fractalkine, high-fat diet, CCL20, IL-17A

\section{INTRODUCTION}

Obesity is an important risk factor for the development of asthma $(1-5)$. Obesity-related asthma is more prevalent among women and is typically non-atopic in nature $(6,7)$. Importantly, in obese non-atopic asthmatics, airway hyperresponsiveness (AHR), a defining feature of asthma, can be attenuated by weight loss (6, 8). Obesity decreases the efficacy of asthma control medications $(5,9)$, making these patients difficult to treat. Understanding the mechanistic basis for obesity-related asthma may allow for the development of therapeutics that is effective in this population.

Innate AHR is a common feature of obese mice, suggesting that these mice may be useful in understanding the relationship between obesity and asthma. Mice that are genetically deficient in leptin or its receptor ( $o b / o b$ or $d b / d b$ mice) and mice that are genetically deficient in carboxypeptidase E, an enzyme involved in processing neuropeptides involved in eating behaviors $\left(C p e^{f a t}\right.$ mice) each exhibit AHR compared to age- and gendermatched wildtype (WT) mice (10-13). Mice rendered obese by placing them on high-fat diets (HFD) also develop AHR over time $(14,15)$.

IL-17A has been linked to the development of innate AHR in obese mice (15): compared to chow, HFD feeding results in both obesity and AHR in WT mice, whereas AHR is not observed in mice deficient in IL-17A despite equal induction of obesity. To further evaluate the role of IL-17A, we examined the temporal association between the development of AHR and changes in IL17A in C57BL/6J mice fed chow or a HFD for up to 24 weeks. Our results indicated an increase in Il17a mRNA abundance in lung tissue that preceded the development of AHR in HFD versus chow fed mice.

A previous microarray analysis comparing gene expression in lung tissue from obese $C p e^{f a t}$ versus lean WT mice identified several genes that were significantly affected by obesity (16). Because of the requirement for IL-17A for induction of AHR by HFD (15), we searched for evidence linking IL-17A to expression of these genes to assist in determining how IL-17A might lead to AHR. 
Among these genes, we identified two, $C f d$ (complement factor D/adipsin) and Cx3cl1 (fractalkine), whose expression is reported to be affected by IL-17A $(17,18)$. Hence, we also examined the temporal association between the development of AHR, pulmonary Ill7a mRNA expression, and pulmonary $C f d$ and $C \times 3 c l 1$ mRNA expression in mice fed chow or HFD for up to 24 weeks. There was no effect of HFD on pulmonary $C x 3 c l 1$ expression, but pulmonary $C f d$ expression significantly declined in HFD versus chow fed mice, consistent with previously reported declines in pulmonary $C f d$ expression in $C p e^{f a t}$ mice (16). Moreover, changes in $C f d$ coincided temporally with changes in $I l 17 a$, and our results indicate a significant correlation between pulmonary $C f d$ expression and both pulmonary $I l 17 a$ and AHR, suggesting that changes in pulmonary Cfd expression contribute to the ability of IL-17A to promote obesity-related AHR.

\section{MATERIALS AND METHODS ANIMALS}

This study was approved by the Harvard Medical Area Standing Committee on Animals. Male C57BL/6J mice were placed on a HFD [Research diet (D12451)] or control normal chow (PicoLab, LabDiet, St. Louis, MO) at weaning (approximately 3 weeks of age). Mice were kept on the diet for 9, 12, 15, 18 or 24 weeks. $\mathrm{Db} / \mathrm{d} b$ and WT (C57BL/6J) controls were purchased from The Jackson Laboratories and housed for 4 weeks before use, during which time they were fed a standard mouse chow diet. $\mathrm{Db} / \mathrm{db}$ mice and their WT controls were 10 weeks old at the time of study.

\section{PROTOCOL}

Baseline pulmonary mechanics and airway responsiveness to inhaled aerosolized methacholine were assessed in otherwise unchallenged chow fed or HFD fed mice. Mice were assessed 9, $12,15,18$, or 24 weeks after initiation of the diet. After lung function measurements, mice were euthanized, blood was collected by right ventricular puncture, and bronchoalveolar lavage (BAL) was performed. The lungs were then flushed of blood by injecting $10 \mathrm{ml}$ of cold PBS through the right ventricle after creating a large excision in the left ventricle. The left lung was excised and used for flow cytometry. The right lung was excised and placed in RNAlater (Qiagen, Germantown, MD, USA) for subsequent preparation of RNA for real time PCR.

\section{MEASUREMENT OF PULMONARY MECHANICS AND AIRWAY RESPONSIVENESS}

Mice were anesthetized with sodium pentobarbital $(50 \mathrm{mg} / \mathrm{kg})$ and xylazine $(7 \mathrm{mg} / \mathrm{kg})$ and instrumented for the measurement of pulmonary mechanics and airway responsiveness to methacholine by the forced oscillation technique using a Flexivent system (SciReq, Montreal, QC, Canada). The chest wall was opened bilaterally to expose the lungs to atmospheric pressure and a positive end expiratory pressure of $3 \mathrm{~cm} \mathrm{H}_{2} \mathrm{O}$ was applied. Volume history was standardized by thrice inflating the lungs to $30 \mathrm{~cm} \mathrm{H}_{2} \mathrm{O}$ airway opening pressure. Pulmonary mechanics were then assessed after inhalation of aerosolized PBS and after successive aerosolizations of methacholine in concentrations increasing in half log increments from 0.3 to $100 \mathrm{mg} / \mathrm{ml}$. Inflation to $30 \mathrm{~cm} \mathrm{H}_{2} \mathrm{O}$ followed completion of measurements at each concentration and the next aerosolization was initiated $1 \mathrm{~min}$ after this inflation. The following parameters were measured, as previously described (19), every $15 \mathrm{~s}$ for $3 \mathrm{~min}$ after each concentration of methacholine: Newtonian resistance $(\mathrm{Rn})$, which largely reflects the conducting airways, and the coefficients of lung tissue damping $(G)$ and lung tissue elastance $(\mathrm{H})$, which reflect changes in the lung tissue, including airway closure. At each concentration of methacholine, the three highest values of Rn, G, and $\mathrm{H}$ were averaged and used to construct dose response curves. We also calculated the effective concentration of methacholine required to double G (EC200G) by log linear interpolation between the two doses bounding the point where $G$ is doubled.

\section{BRONCHOALVEOLAR LAVAGE}

Bronchoalveolar lavage was performed by twice instilling and withdrawing $1 \mathrm{ml}$ of PBS. BAL was spun and the pelleted cells counted as previously described (20). BAL supernatant was stored at $-80^{\circ} \mathrm{C}$ until assayed for complement factor D (adipsin, Apcam, Cambridge, MA, USA), IL-17A (Biolegend, San Diego, CA, USA), and IL-23 (eBioscience, San Diego, CA, USA).

\section{REAL TIME qPCR}

Total RNA was prepared as previously described (21). RNA concentration and purity was determined using a small volume spectrophotometer (Nanodrop, Thermo Scientific, USA). RNA was converted into cDNA using a commercial kit (SuperScript III for qRT-PCR, Invitrogen). All expression values were normalized to 36B4 expression using the $\Delta \Delta \mathrm{Ct}$ method. Primers for Rplp0 (36B4), Cfd, Cx3cl1, Il23a (p19), Il17a, and Ccl20 (MIP3 $\alpha$ ) have all been described previously $(16,22)$. Primers for $I l 1 \alpha$ were forward - CGGCAAAGAAATCAAGATGG and reverse TTCAGAGAGAGATGGTCAATGG; for Il1 $\beta$ forward - CTGTGTCTTTCCCGTGGACC and reverse - CAGCTCATATGGGTCCGACA; and for IL-6 forward - CCGGAGAGGAGACTTCACAG and reverse - CAGAATTGCCATTGCACAAC.

\section{FLOW CYTOMETRY}

Left lungs were harvested and placed on ice in RPMI 1640 media containing 2\% FBS and HEPES. Lungs were digested, prepared for flow cytometry, and analyzed as previously described (22). The following antibodies were used: Alexa Fluor 647 anti-IL-17A (clone: TC11-18H10.1), PE anti-TCR $\delta$ (clone: GL3), PE-cy7 anti-CD45 (clone: 30-F11), and Alexa Flour 488 anti-CD4 (clone: GK1.5) (all antibodies from Biolegend). These antibodies were used to determine the total number of CD4 cells, $\gamma \delta$ T cells, IL-17A ${ }^{+} \gamma \delta$ T cells, IL- $17 \mathrm{~A}^{+} \mathrm{CD} 45^{+}$cells, and IL-17A ${ }^{+} \mathrm{CD} 4^{+} \mathrm{T}$ cells.

\section{SERUM CYTOKINES}

Serum was prepared from harvested blood using microtainer tubes (Becton Dickinson, NJ, USA) and stored at $-80^{\circ} \mathrm{C}$ until assayed. Serum cytokines and chemokines were assayed by multiplex assay as previously described $(10,16)$ (Eve Technologies, Calgary, AB, Canada). We used ELISA to assay serum IL-17A and TNF $\alpha$ (Biolegend for IL-17A and R\&D Systems for TNF $\alpha$ ).

\section{STATISTICS}

Data were analyzed by factorial ANOVA using STATISTICA software (StatSoft, Tulsa, OK, USA), with diet and weeks on diet 
as main effects. Fisher's least significant difference test was used as a post hoc test. A $p$ value $<0.05$ was considered statistically significant.

\section{RESULTS}

\section{BODY MASS}

Factorial ANOVA indicated that both the type $(p<0.001)$ and duration $(p<0.001)$ of the diet had a significant effect on body mass (Figure 1). In both chow fed and HFD fed mice, body mass increased with time. Additionally, body mass was significantly higher in the HFD than the chow fed mice at all-time points except 9 weeks.

\section{PULMONARY MECHANICS AND AIRWAY RESPONSIVENESS}

Obesity increases baseline pulmonary mechanics in mice (10, $11,16)$. We examined the development of these changes with HFD. Factorial ANOVA indicated no significant effect of HFD feeding on $\mathrm{Rn}$, though there was a significant effect of time on the diet $(p<0.02)$, possibly as a result of lung and airway growth (Figure $2 \mathrm{~A}$ ). In contrast, both $\mathrm{G}$ and $\mathrm{H}$ were significantly increased in HFD versus chow fed mice $(p<0.01)$ (Figures 2B,C).

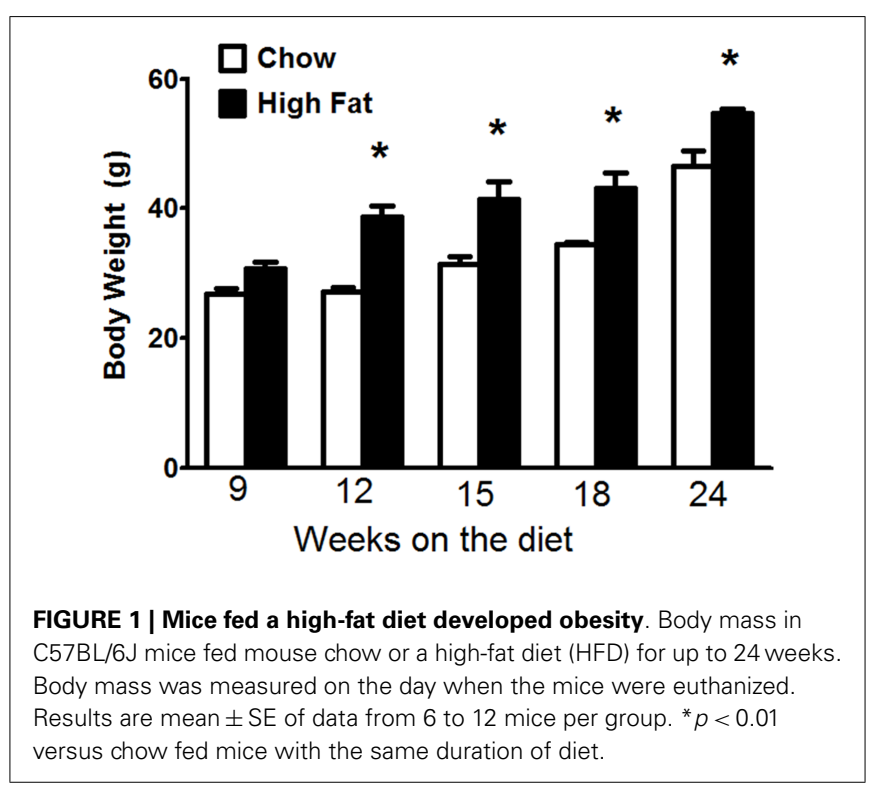

Increases in $\mathrm{G}$ and $\mathrm{H}$ were observed by 18 weeks on the diet and sustained through 24 weeks. Compared to chow fed mice, HFD fed mice had significantly greater airway responsiveness and a corresponding significantly reduced EC200G after 24 weeks on the diet, whereas there was no consistent difference at earlier time points (Figure 3 ). Results shown in Figure 3 indicate the response to methacholine as measured by changes in G. Essentially, similar results were obtained for $\mathrm{H}$, which can be impacted by airway closure, whereas no change in responsiveness was observed using $\mathrm{Rn}$ as the outcome indicator (data not shown).

\section{IL-17A IS ELEVATED IN LUNGS OF HFD VERSUS CHOW FED MICE}

Mice deficient in IL-17A do not develop AHR with highfat feeding (15), suggesting an important role for IL-17A in the development of the innate AHR of obesity. Consequently, we explored the temporal relationship between the onset of IL-17A expression and the pulmonary phenotype induced by HFD. Neither serum nor BAL IL-17A was affected by the HFD (Figures 4A,B). In contrast, qPCR indicated greater pulmonary Ill7a mRNA abundance in HFD versus chow fed mice after both 18 and 24 weeks on the diet (Figure 4C). Flow cytometry on cells dissociated from lungs of mice after 24 weeks on the diet confirmed an increase in $\mathrm{IL}-17 \mathrm{~A}^{+} \mathrm{CD} 45^{+}$cells in lungs of HFD versus chow fed mice (Figure 4D) and also indicated increases in both IL-17A ${ }^{+} \gamma \delta \mathrm{T}$ cells and IL-17A ${ }^{+} \mathrm{CD} 4^{+}$ (Th17) cells (Figures 4E,F). There was also a significant increase in total $\gamma \delta \mathrm{T}$ cells, whereas total $\mathrm{CD}^{+}$cells were unchanged (Figures 4G,H).

To examine potential causes for the increase in Il17a mRNA expression in HFD fed mice (Figure 4C), we examined the time course of changes in Illa, IL1b, Il23a, Il6, and Ccl20. IL-1 $\alpha$, IL$1 \beta$, IL-6, and IL-23 are each drivers of IL-17A production (23) and CCL20 is a chemoattractant for IL-17A producing T cells (24). Factorial ANOVA indicated an effect of duration $(p<0.05)$ but not type of diet on Ccl20 mRNA abundance. Follow up analysis indicated that the difference lay in the 24-week-mice, which exhibited increased $\mathrm{Ccl} 20$ mRNA compared to other time points (Figure 5). Neither BAL IL-23 nor pulmonary Il23a mRNA expression was impacted by the type or duration of dietary feeding, nor was there any impact on pulmonary $I l 1 a, I L 1 b$, or $I l 6$ mRNA expression (data not shown).
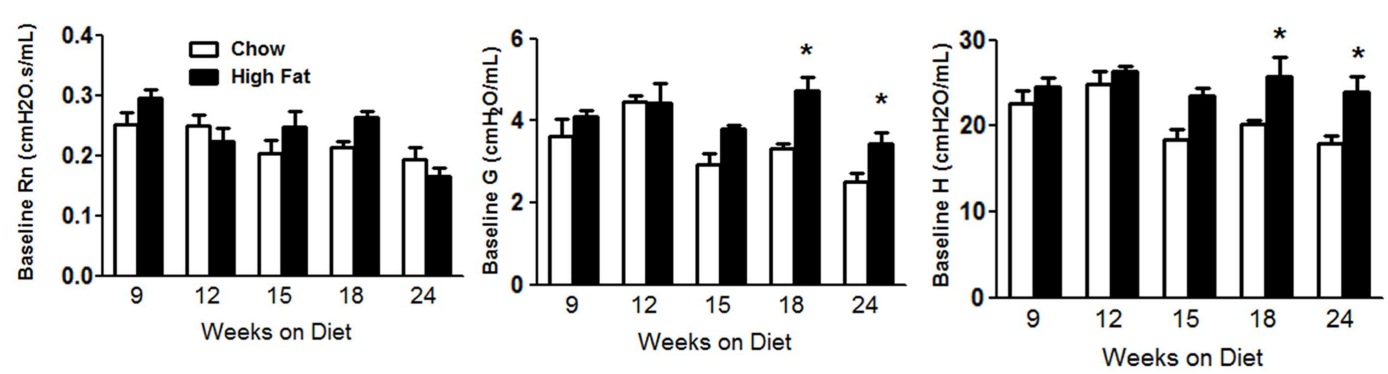

FIGURE 2 | High-fat feeding increased baseline pulmonary mechanics Baseline pulmonary mechanics in mice fed chow or HFD for up to 24 weeks. $\mathrm{Rn}$, Newtonian resistance; $\mathrm{G}$ and $\mathrm{H}$, coefficients of lung tissue damping and lung tissue elastance, respectively. Results are mean \pm SE of data from five to nine mice per group. ${ }^{*} p<0.05$ versus chow fed mice with the same duration of diet. 


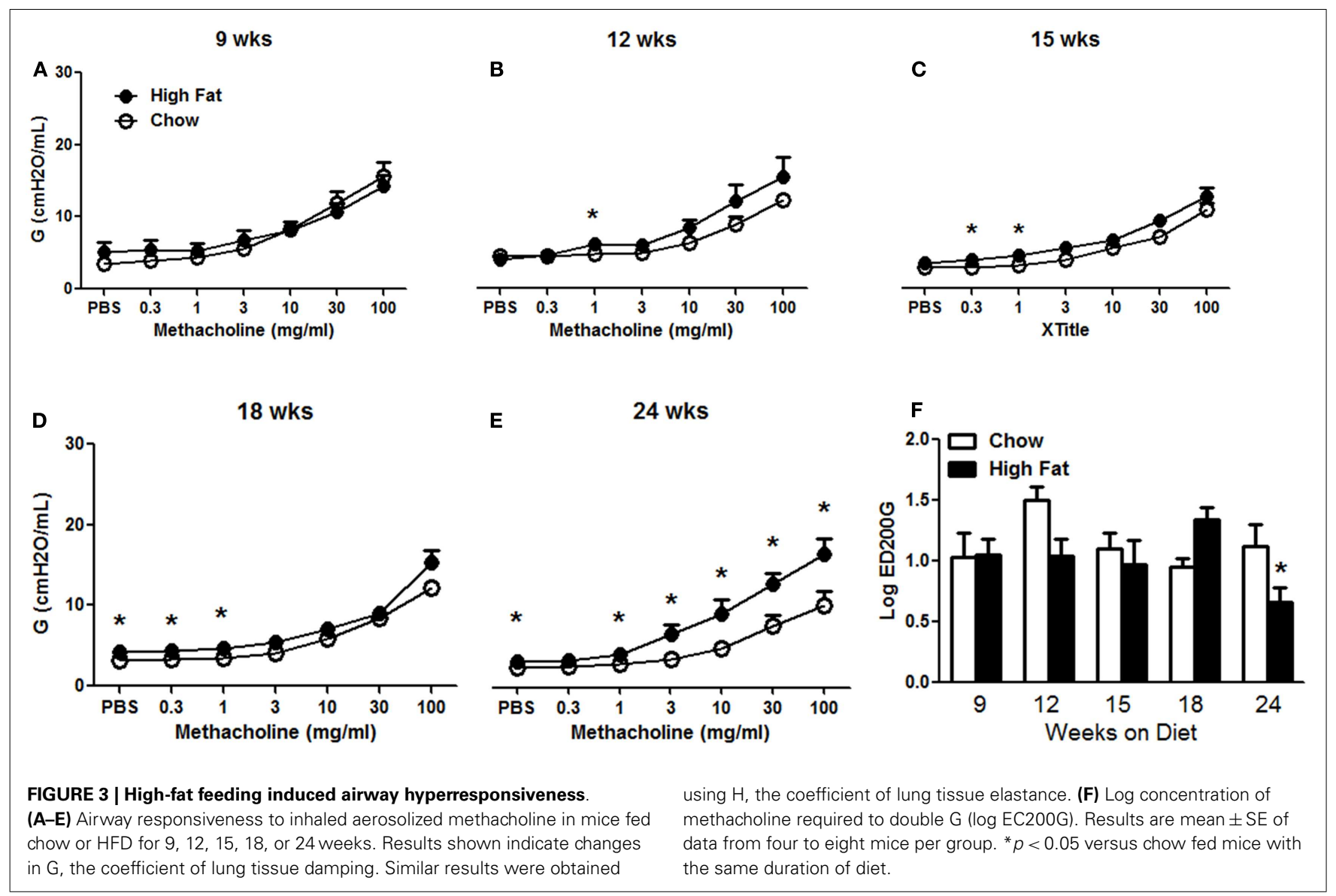

\section{POSSIBLE ROLE OF ADIPSIN}

To determine how IL-17A might lead to AHR, we revisited a microarray analysis of genes whose expression is significantly different in lungs of obese $C p e^{f a t}$ versus lean WT mice (16). Among these genes, two genes, $C f d$ and $C x 3 c l 1$, whose mRNA expression levels are reduced in lungs of $C p e^{f a t}$ versus WT mice (10, 16), have also been shown to be impacted by IL-17A. In particular, IL-17A reduces $C f d$ mRNA expression in adipose tissue (18) and reduces $C x 3 c l 1$ expression in ocular endothelial cells (21). qPCR confirmed a time-dependent decrease in pulmonary $C f d$ mRNA abundance in HFD versus chow fed mice (Figure 6A), consistent with previous observations in lungs of $C p e^{f a t}$ mice. Significant differences were observed at 18 and 24 weeks of diet (Figure 6A), the same time points where diet-related changes in Ill7a mRNA were observed (Figure 4C). Because we have also observed innate AHR in $d b / d b$ versus WT mice, we also measured $C f d$ expression in $d b / d b$ mice to determine if changes in pulmonary $C f d$ expression were consistent across the multiple forms of obesity that exhibit AHR. We observed significantly reduced $C f d$ mRNA expression in lungs of obese $d b / d b$ versus lean WT mice (Figure 6B). BAL adipsin was also reduced in both HFD versus chow fed mice $(p<0.01)$ and in $d b / d b$ versus WT mice $(p<0.05)$ (Figures 6C,D). Importantly, in the 24-weekmice, there was a correlation between $C f d$ mRNA and Il17a mRNA expression (Figure 7A) and between $C f d$ mRNA and the EC200G
(Figure 7B), an index of AHR. In contrast, there was no significant difference in pulmonary $C \times 3 \mathrm{cl} 1 \mathrm{mRNA}$ abundance between chow fed and HFD fed mice, or between WT and $d b / d b$ mice, although there was a trend toward reduced $C \times 3 c l 1$ mRNA abundance in both types of obesity (Figures 6E,F).

\section{SYSTEMIC INFLAMMATION}

Low grade systemic inflammation is now recognized as a common feature of obesity and has been shown to contribute to a wide variety of the comorbidities of obesity including type 2 diabetes (25) and atherosclerosis (26). Increases in pulmonary Ill7a expression preceded the induction of AHR by several weeks (Figure 4C), suggesting the additional involvement of factors that developed more slowly. To determine if obesity-induced systemic inflammation might be one of these factors, we measured multiple cytokines in the serum by multiplex assay over the course of development of obesity. Factorial ANOVA indicated that compared to chow feeding, high-fat feeding caused a time-dependent increase in serum MIP- $1 \alpha$, MIP- $1 \beta$, and TNF $\alpha(p<0.05$ in each case) (Figures 8A-C), consistent with observations of others (25, $27,28)$. While there was a trend toward increases in all three of these moieties after 18 weeks on the diet, the effect did not achieve statistical significance until 24 weeks. We also observed significantly greater IL-2 in serum of 24 -week-old HFD versus chow fed mice (Figure 8D). 


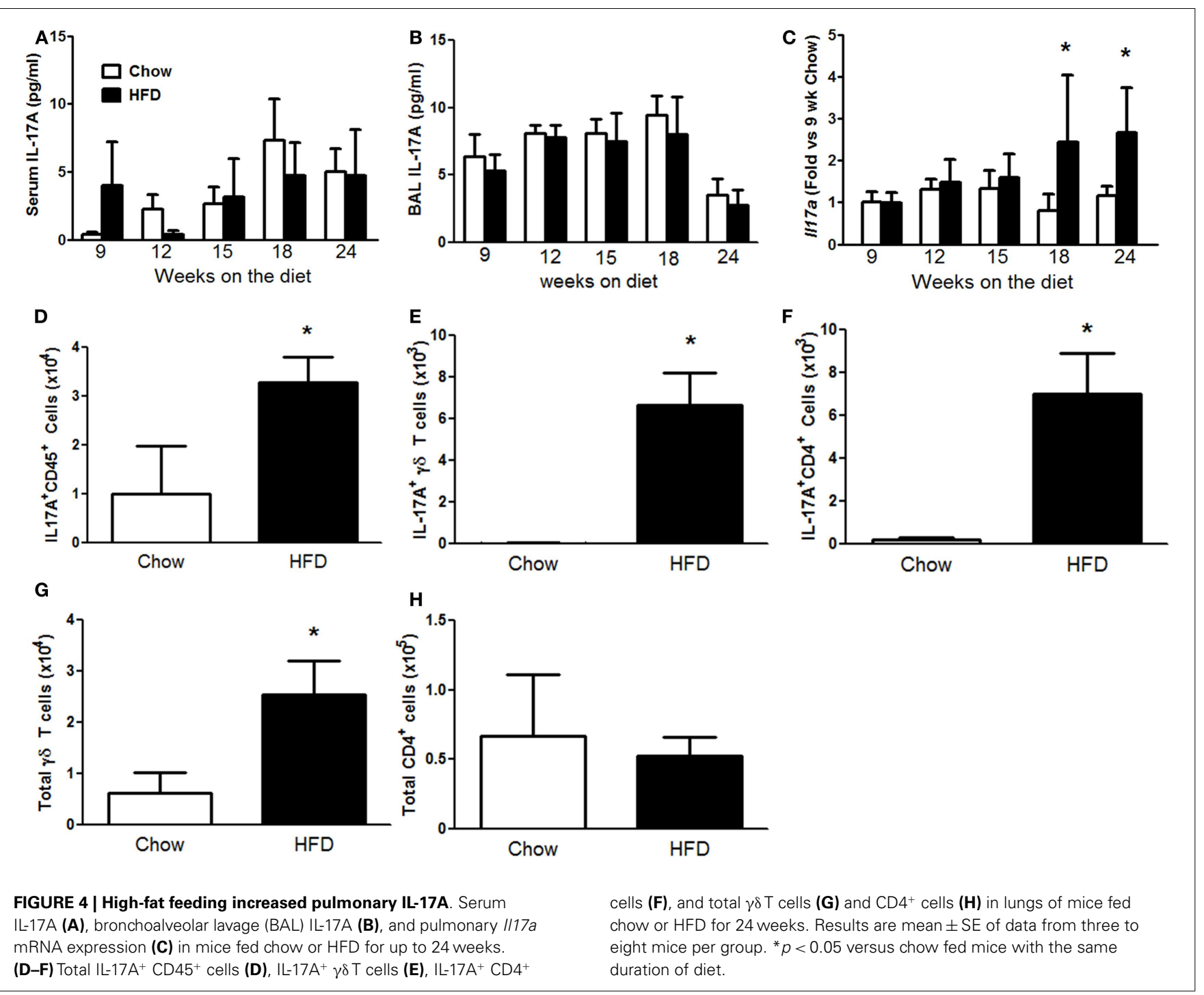

\section{DISCUSSION}

Body mass was significantly greater in HFD than chow fed mice after 12 weeks of diet (Figure 1). This difference was maintained through 24 weeks. Nevertheless, compared to chow fed mice, HFD fed mice did not develop changes in pulmonary mechanics until 18 weeks (Figure 2) and did not develop AHR until 24 weeks on the diet (Figure 3), even though the magnitude of differences in body mass was no greater at this time than at 12 weeks of diet (Figure 1). This delay between the onset of obesity and the onset of AHR is consistent with previous observations in HFD fed mice (14), and may be the result of the time required for the induction of conditions necessary for recruitment of $\mathrm{IL}-17 \mathrm{~A}^{+}$cells to the lung. IL-17A is required for the development of AHR in HFD fed mice (15), and we also observed a delay between the onset of increases in body mass (Figure 1) and the onset of increases in pulmonary Il17a expression (Figure 4C). Indeed, the induction of significant changes in pulmonary $I l 17 a$ expression (Figure 4C) by HFD coincided with increases in pulmonary mechanics (Figure 2) and preceded the development of AHR by several weeks (Figure 3).
Our data suggest that obesity-related reductions in pulmonary Cfd expression may contribute to effects of IL-17A that promote obesity-related AHR. Obesity-related AHR is observed not just in mice rendered obese by high-fat feeding (Figure 3) but also in obese $d b / d b$ (11) and obese $C p e^{f a t}$ mice (29). Similarly, pulmonary expression of $C f d$ was reduced in all three types of obese mice [Figures $6 \mathbf{A}, \mathbf{B}$ for HFD and $d b / d b$ mice and $(10,16)$ for $C p e^{f a t}$ mice]. Decreased complement factor D has also been reported in the serum and adipose tissue (30) and in the liver (31) of obese mice. Importantly, changes in pulmonary $C f d$ expression coincided temporally with changes in pulmonary $I l 17 a$ expression (Figure 4C). Additionally, we observed a significant inverse correlation between pulmonary expression of $C f d$ and $I l 17 a$ (Figure 7A) in the 24-week-mice (at which time AHR was present in the HFD mice). The correlation between $I l 17 a$ and $C f d$ (Figure 7A) is consistent with reports of decreased $C f d$ expression in adipocytes treated with IL-17A (18). Importantly, pulmonary $C f d$ expression also correlated with AHR (Figure 7B). 
The mechanistic basis for the relationship between pulmonary $C f d$ expression and AHR is not established. Complement factor D cleaves factor B after it has bound to $\mathrm{C} 3$ (H20) resulting in activation of the alternatively activated complement pathway (32). Others have reported reduced allergen induced AHR in factor B-deficient and C3a-deficient mice. These data suggest that attenuated activation of the alternative pathway, as would

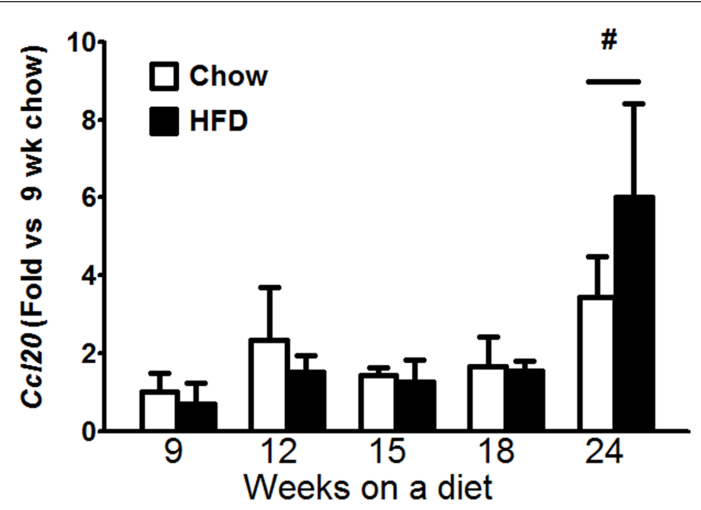

FIGURE 5 | Pulmonary Cc/20 mRNA expression increased with time on diet. Pulmonary CCl20 mRNA expression in mice fed chow or HFD for up to 24 weeks. Results are mean \pm SE of data from four to eight mice per group. ${ }^{\#} p<0.05$ versus other durations of diet be expected with the reduced $C f d$ expression observed in obese mice [Figures 6A,B $(31,33)$ ], would reduce, not augment airway responsiveness as observed in obese mice (Figure 3). However, there is some evidence that complement can also serve a protective role in the lung. Lung injury occurs in multiple models of liver injury and depletion of complement with cobra venom factor in mice with liver injury increases NF- $\kappa \mathrm{B}$ activation and inflammation in the lung (34), events that might be expected to promote AHR. In this context, it is important to note that liver pathology is a common feature of obese mice (35). In addition, using a bioinformatics approach, Couto Alves et al. (36) identified significant interactions between $\mathrm{T}$ cell activation and the complement system in patients with allergic rhinitis, including reductions in expression of most complement species, including CFD.

Increases in serum IL-17A are observed both in Cpe $e^{f a t}$ mice (16) and in $d b / d b$ mice (unpublished observations) and serum IL-17A is also elevated in obese human subjects (37). However, there was no change in serum IL-17A with either the type or duration of diet (Figures 4A,B). The substantially greater increases in body mass extant in the genetically obese $C p e^{f a t}$ and $d b / d b$ mice than in HFD mice may explain this apparent discrepancy. However, the absence of increases in serum IL-17A (Figure 4A) despite increases in AHR (Figure 3) with HFD, in conjunction with the observations that obesity-related AHR does not occur in IL-17A-deficient mice (15), suggest that the source of the IL-17A that is important for AHR is the lung not the blood. Indeed, we observed increases in IL-17 ${ }^{+}$

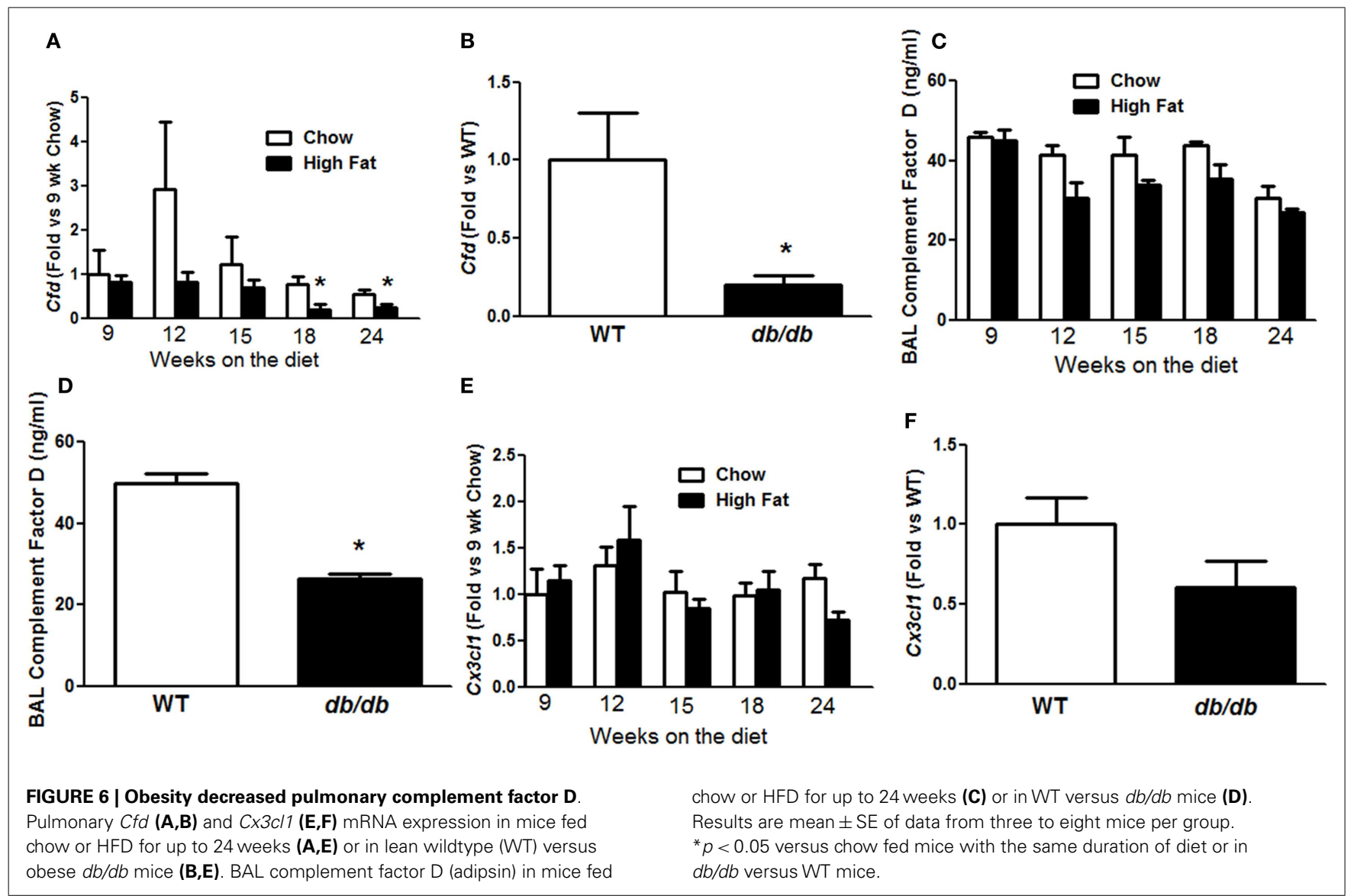


cells in the lung tissue of HFD versus chow fed mice (Figure 4). IL-17A expressing cells were only examined at 24 weeks, the time point at which we observed AHR (Figure 3). We did not examine ILC17 cells, but did observe increases in both IL-17A ${ }^{+} \gamma \delta \mathrm{T}$ cells and Th17 cells (Figure 4), consistent with the observations of others (15). The observation that IL-17A producing cells are increased by HFD feeding is not unique to the lung. Compared to chow, HFD also increases the number of IL-17A ${ }^{+}$cells in other organs and tissues, including spleen, liver, and joints (38-40).

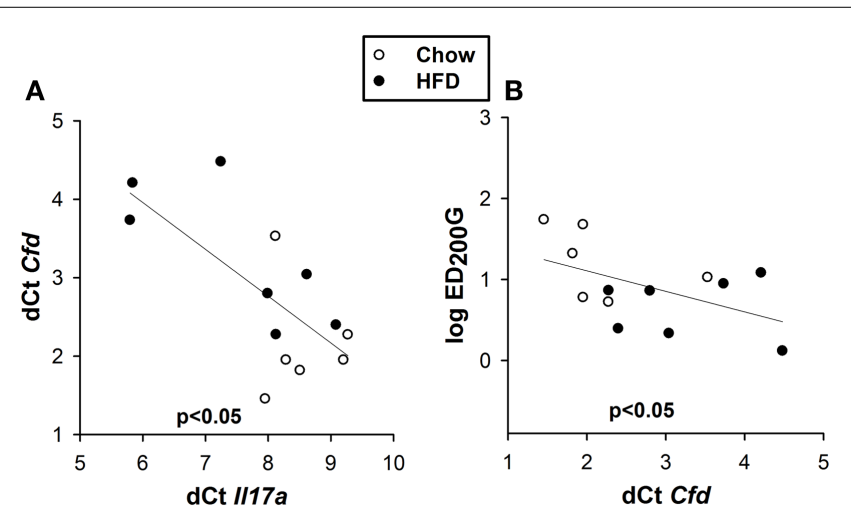

FIGURE 7 | Pulmonary Cfd correlates with pulmonary II17a and AHR. Correlation between pulmonary Cfd and I/17a mRNA expression (A) and between log EC200G and pulmonary Cfd mRNA expression (B) in mice fed chow or HFD for 24 weeks. Note that reductions in EC200G indicate increased airway responsiveness and that increases in $d C t$ indicate reductions in the expression of that gene.
We found no evidence of a role for either IL-6 or IL-23 in the induction of pulmonary IL-17A ${ }^{+} \mathrm{T}$ cells during HFD. Instead, leptin, an adipose-derived hormone that increases in obesity may be involved. The mechanistic basis for effects of IL- 6 and IL-23 on IL-17A involves activation of STAT3 (41), and leptin also induces STAT3 activation (42). Indeed, leptin receptors are expressed on $\mathrm{T}$ cells and leptin can induce the differentiation of $\mathrm{T}$ cells into IL17A producing cells (43). We also observed increased pulmonary mRNA expression of $\mathrm{Ccl} 20$, a chemoattractant for IL-17A producing cells, after 24 weeks (Figure 5), though there was no significant difference in $\mathrm{Ccl} 20$ expression between chow and HFD mice. Such increases, in conjunction with leptin-mediated increases in circulating IL-17A ${ }^{+} \mathrm{T}$ cells in the HFD mice, would be expected to increase the number of IL-17A ${ }^{+}$cells in the lungs.

The co-incident changes in pulmonary mechanics (Figure 2) and pulmonary Il17a expression (Figure 4C) may be the result of direct effects of IL-17A on airway smooth muscle that promote contractility (44). Increases in G and H occur not only with HFD but also in $C p e^{f a t}, d b / d b$, and $o b / o b$ mice $(10,11,13,16)$, and may be the result of small airway closure, a phenomenon that also occurs in human obesity (45-48). However, the observation that increases in pulmonary Il17a expression preceded the development of AHR suggests that factors in addition to IL-17A are required for the induction of AHR. Our data suggest that the systemic inflammation of obesity may be one of these factors. There was a delay between the onset of increases in body mass and the onset of systemic inflammation (Figure 8) consistent with previous reports (49), but the onset of systemic inflammation (Figure 8) was coincident with the development of AHR (Figure 3), both being observed at 24 weeks of diet but not earlier. In other systems,
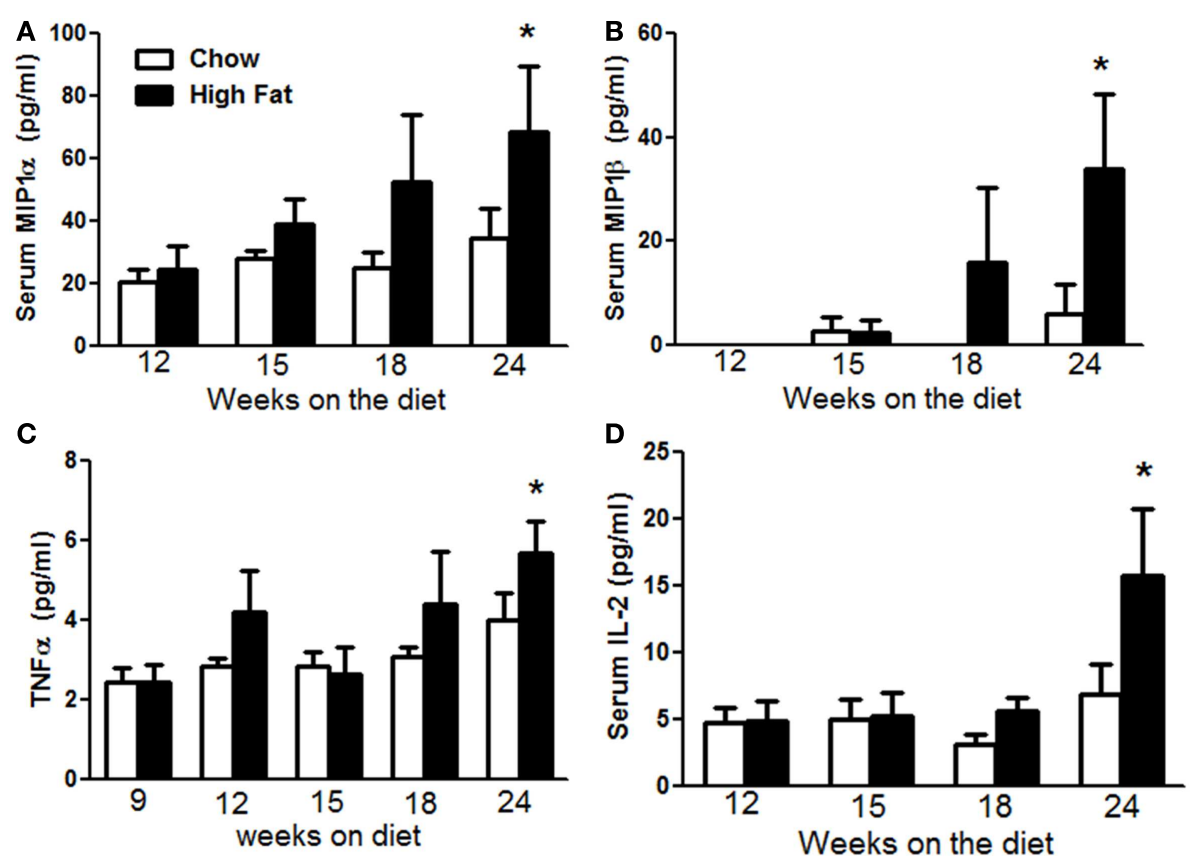

FIGURE 8 | High-fat feeding caused systemic inflammation. Serum MIP-1 $\alpha$ (A), MIP-1 $\beta$ (B), TNF $\alpha$ (C), and IL-2 (D) in mice fed chow or HFD for up to 24 weeks. Results are mean \pm SE of data from six to nine mice per group. ${ }^{*} p<0.05$ versus chow fed mice with the same duration of diet. 
IL-17A synergizes with other cytokines including TNF $\alpha$ to promote changes in cell function (50) and similar synergistic effects of TNF $\alpha$ and IL-17A may be necessary to drive AHR in obesity. The observations that both IL-17A (15) and TNFR2 (16) are required for the development of AHR in obese mice are consistent with this hypothesis.

In conclusion, it has been previously established that IL-17A is required for obesity-related AHR. Data presented here extend those observations by showing that pulmonary rather than systemic IL-17A is important for obesity-related AHR and suggest that changes in pulmonary $C f d$ expression contribute to the AHR-promoting effects of IL-17A. Further, the observations that increases in pulmonary $I l 17 a$ mRNA expression preceded, whereas the onset of the systemic inflammation of obesity coincided temporally with the development of AHR suggest that systemic inflammation may interact with IL-17A to promote AHR.

\section{ACKNOWLEDGMENTS}

This study was supported by National Institutes of Environmental Health Sciences grants ES-013307, ES-000002, and ES022556.

\section{REFERENCES}

1. Beuther DA, Sutherland ER. Overweight, obesity, and incident asthma. Am J Respir Crit Care Med (2007) 175(7):661-6. doi:10.1164/rccm.200611-1717OC

2. Ford ES. The epidemiology of obesity and asthma. J Allergy Clin Immunol (2005) 115(5):897-909. doi:10.1016/j.jaci.2004.11.050

3. Litonjua AA, Gold DR. Asthma and obesity: common early-life influences in the inception of disease. J Allergy Clin Immunol (2008) 121(5):1075-84. doi:10.1016/j.jaci.2008.03.005 quiz 85-6,

4. Shore SA, Johnston RA. Obesity and asthma. Pharmacol Ther (2006) 110(1):83-102. doi:10.1016/j.pharmthera.2005.10.002

5. Wenzel SE. Asthma phenotypes: the evolution from clinical to molecular approaches. Nat Med (2012) 18(5):716-25. doi:10.1038/nm.2678

6. Dixon AE, Pratley RE, Forgione PM, Kaminsky DA, Whittaker-Leclair LA, Griffes LA, et al. Effects of obesity and bariatric surgery on airway hyperresponsiveness, asthma control, and inflammation. J Allergy ClinImmunol (2011) 128(3):508.e-15.e. doi:10.1016/j.jaci.2011.06.009

7. Chen H, Blanc PD, Kamath T, Lee JH, Sullivan SD. Assessing the impact of asthma control on quality of life in patients with severe or difficult-to-treat asthma. CHEST J (2006) 130:95S-d-6S. doi:10.1378/chest.130.3.890

8. Maniscalco M, Zedda A, Faraone S, Cerbone MR, Cristiano S, Giardiello C, et al. Weight loss and asthma control in severely obese asthmatic females. Respir Med (2008) 102(1):102-8. doi:10.1016/j.rmed.2007.07.029

9. Sutherland ER, Lehman EB, Teodorescu M, Wechsler ME. Body mass index and phenotype in subjects with mild-to-moderate persistent asthma. J Allergy Clin Immunol (2009) 123(6):1328.e-34.e. doi:10.1016/j.jaci.2009.04.005

10. Zhu M, Williams AS, Chen L, Wurmbrand AP, Williams ES, Shore SA. Role of TNFR1 in the innate airway hyperresponsiveness of obese mice. J Appl Physiol (2012) 113(9):1476-85. doi:10.1152/japplphysiol.00588.2012

11. Lu FL, Johnston RA, Flynt L, Theman TA, Terry RD, Schwartzman IN, et al. Increased pulmonary responses to acute ozone exposure in obese $\mathrm{db} / \mathrm{db}$ mice. Am J Physiol Lung Cell Mol Physiol (2006) 290(5):L856-65. doi:10.1152/ajplung. 00386.2005

12. Arteaga-Solis E, Zee T, Emala Charles W, Vinson C, Wess J, Karsenty G. Inhibition of leptin regulation of parasympathetic signaling as a cause of extreme body weight-associated asthma. Cell Metab (2013) 17(1):35-48. doi:10.1016/j. cmet.2012.12.004

13. Shore SA, Rivera-Sanchez YM, Schwartzman IN, Johnston RA. Responses to ozone are increased in obese mice. J Appl Physiol (2003) 95(3):938-45. doi:10.1152/japplphysiol.00336.2003

14. Johnston RA, Theman TA, Lu FL, Terry RD, Williams ES, Shore SA. Diet-induced obesity causes innate airway hyperresponsiveness to methacholine and enhances ozone-induced pulmonary inflammation. JAppl Physiol (2008) 104(6):1727-35. doi:10.1152/japplphysiol.00075.2008
15. Kim HY, Lee HJ, Chang YJ, Pichavant M, Shore SA, Fitzgerald KA, et al. Interleukin-17-producing innate lymphoid cells and the NLRP3 inflammasome facilitate obesity-associated airway hyperreactivity. Nat Med (2014) 20(1):54-61. doi:10.1038/nm.3423

16. Williams AS, Chen L, Kasahara DI, Si H, Wurmbrand AP, Shore SA. Obesity and airway responsiveness: role of TNFR2. Pulm Pharmacol Ther (2013) 26(4):444-54. doi:10.1016/j.pupt.2012.05.001

17. Silverman MD, Zamora DO, Pan Y, Texeira PV, Baek SH, Planck SR, et al. Constitutive and inflammatory mediator-regulated fractalkine expression in human ocular tissues and cultured cells. Invest Ophthalmol Vis Sci (2003) 44(4):1608-15. doi:10.1167/iovs.02-0233

18. Zuniga LA, Shen WJ, Joyce-Shaikh B, Pyatnova EA, Richards AG, Thom C, et al. IL-17 regulates adipogenesis, glucose homeostasis, and obesity. J Immunol (2010) 185(11):6947-59. doi:10.4049/jimmunol.1001269

19. Johnston RA, Zhu M, Hernandez CB, Williams ES, Shore SA. Onset of obesity in carboxypeptidase E-deficient mice and effect on airway responsiveness and pulmonary responses to ozone. J Appl Physiol (2010) 108(6):1812-9. doi:10.1152/japplphysiol.00784.2009

20. Kasahara DI, Kim HY, Williams AS, Verbout NG, Tran J, Si H, et al. Pulmonary inflammation induced by subacute ozone is augmented in adiponectin-deficient mice: role of IL-17A. J Immunol (2012) 188(9):4558-67. doi:10.4049/jimmunol. 1102363

21. Shore SA, Williams ES, Chen L, Benedito LAP, Kasahara DI, Zhu M. Impact of aging on pulmonary responses to acute ozone exposure in mice: role of TNFR1. Inhal Toxicol (2011) 23(14):878-88. doi:10.3109/08958378.2011.622316

22. Mathews JA, Williams AS, Brand JD, Wurmbrand AP, Chen L, Ninin FM, et al. Gammadelta T Cells are required for pulmonary IL-17A expression after ozone exposure in mice: role of TNFalpha. PLoS One (2014) 9(5):e97707. doi:10.1371/journal.pone.0097707

23. Korn T, Bettelli E, Oukka M, Kuchroo VK. IL-17 and Th17 Cells. Annu Rev Immunol (2009) 27:485-517. doi:10.1146/annurev.immunol.021908.132710

24. Hirota K, Yoshitomi H, Hashimoto M, Maeda S, Teradaira S, Sugimoto N, et al. Preferential recruitment of CCR6-expressing Th17 cells to inflamed joints via CCL20 in rheumatoid arthritis and its animal model. J Exp Med (2007) 204(12):2803-12. doi:10.1084/jem.20071397

25. Hotamisligil GS, Shargill NS, Spiegelman BM. Adipose expression of tumor necrosis factor-alpha: direct role in obesity-linked insulin resistance. Science (1993) 259(5091):87-91. doi:10.1126/science.7678183

26. Linton MF, Fazio S. Macrophages, inflammation, and atherosclerosis. Int J Obes Relat Metab Disord (2003) 27(Suppl 3):S35-40. doi:10.1038/sj.ijo.0802498

27. Chiang S-H, Bazuine M, Lumeng CN, Geletka LM, Mowers J, White NM, et al. The protein kinase ikk $\varepsilon$ regulates energy balance in obese mice. Cell (2009) 138(5):961-75. doi:10.1016/j.cell.2009.06.046

28. Yepuru M, Eswaraka J, Kearbey JD, Barrett CM, Raghow S, Veverka KA, et al. Estrogen receptor-\{beta\}-selective ligands alleviate high-fat diet- and ovariectomy-induced obesity in mice. J Biol Chem (2010) 285(41):31292-303. doi:10.1074/jbc.M110.147850

29. Johnston RA, Theman TA, Shore SA. Augmented responses to ozone in obese carboxypeptidase E-deficient mice. Am J Physiol Regul Integr Comp Physiol (2006) 290(1):R126-33. doi:10.1152/ajpregu.00306.2005

30. Flier J, Cook K, Usher P, Spiegelman B. Severely impaired adipsin expression in genetic and acquired obesity. Science (1987) 237(4813):405-8. doi:10.1126/ science. 3299706

31. Shillabeer G, Hornford J, Forden JM, Wong NC, Russell JC, Lau DC. Fatty acid synthase and adipsin mRNA levels in obese and lean JCR:LA-cp rats: effect of diet. J Lipid Res (1992) 33(1):31-9.

32. Xu Y, Ma M, Ippolito GC, Schroeder HW Jr, Carroll MC, Volanakis JE. Complement activation in factor D-deficient mice. Proc Natl Acad Sci U S A (2001) 98(25):14577-82. doi:10.1073/pnas.261428398

33. Frederich RC, Hamann A, Anderson S, Lollmann B, Lowell BB, Flier JS. Leptin levels reflect body lipid content in mice: evidence for diet-induced resistance to leptin action. Nat Med (1995) 1(12):1311-4. doi:10.1038/nm1295-1311

34. Glasgow SC, Kanakasabai S, Ramachandran S, Mohanakumar T, Chapman WC. Complement depletion enhances pulmonary inflammatory response after liver injury. J Gastrointest Surg (2006) 10(3):357-64. doi:10.1016/j.gassur.2005.06. 033

35. Marchesini G, Moscatiello S, Di Domizio S, Forlani G. Obesity-associated liver disease. J Clin Endocrinol Metab (2008) 93(11 Suppl 1):S74-80. doi:10.1210/jc. 2008- 1399 
36. Couto Alves A, Bruhn S, Ramasamy A, Wang H, Holloway JW, Hartikainen $\mathrm{AL}$, et al. Dysregulation of complement system and CD4+ T cell activation pathways implicated in allergic response. PLoS One (2013) 8(10):e74821. doi:10.1371/journal.pone.0074821

37. Sumarac-Dumanovic M, Stevanovic D, Ljubic A, Jorga J, Simic M, StamenkovicPejkovic D, et al. Increased activity of interleukin-23/interleukin-17 proinflammatory axis in obese women. Int J Obes (2009) 33(1):151-6. doi:10.1038/ijo. 2008.216

38. Danzaki K, Matsui Y, Ikesue M, Ohta D, Ito K, Kanayama M, et al. Interleukin-17A deficiency accelerates unstable atherosclerotic plaque formation in apolipoprotein E-deficient mice. Arterioscler Thromb Vasc Biol (2012) 32(2):273-80. doi:10.1161/ATVBAHA.111.229997

39. Harley IT, Stankiewicz TE, Giles DA, Softic S, Flick LM, Cappelletti M, et al. IL-17 signaling accelerates the progression of nonalcoholic fatty liver disease in mice. Hepatology (2014) 59(5):1830-9. doi:10.1002/hep.26746

40. Jhun JY, Yoon BY, Park MK, Oh HJ, Byun JK, Lee SY, et al. Obesity aggravates the joint inflammation in a collagen-induced arthritis model through deviation to Th17 differentiation. Exp Mol Med (2012) 44(7):424-31. doi:10.3858/emm. 2012.44.7.047

41. Subramaniam SV, Cooper RS, Adunyah SE. Evidence for the involvement of JAK/STAT pathway in the signaling mechanism of interleukin-17. Biochem Biophys Res Commun (1999) 262(1):14-9. doi:10.1006/bbrc.1999.1156

42. Ghilardi N, Ziegler S, Wiestner A, Stoffel R, Heim MH, Skoda RC. Defective STAT signaling by the leptin receptor in diabetic mice. Proc Natl Acad Sci U S A (1996) 93(13):6231-5. doi:10.1073/pnas.93.13.6231

43. Deng J, Liu Y, Yang M, Wang S, Zhang M, Wang X, et al. Leptin exacerbates collagen-induced arthritis via enhancement of Th17 cell response. Arthritis Rheum (2012) 64(11):3564-73. doi:10.1002/art.34637

44. Kudo M, Melton AC, Chen C, Engler MB, Huang KE, Ren X, et al. IL-17A produced by [alpha] [beta] $\mathrm{T}$ cells drives airway hyper-responsiveness in mice and enhances mouse and human airway smooth muscle contraction. Nat Med (2012) 18(4):547-54. doi:10.1038/nm.2684

45. Salome CM, King GG, Berend N. Physiology of obesity and effects on lung function. J Appl Physiol (2010) 108(1):206-11. doi:10.1152/japplphysiol.00694. 2009
46. Chapman DG, Berend N, King GG, Salome CM. Increased airway closure is a determinant of airway hyperresponsiveness. Eur Respir J (2008) 32(6):1563-9. doi:10.1183/09031936.00114007

47. Hakala K, Mustajoki P, Aittomaki J, Sovijarvi AR. Effect of weight loss and body position on pulmonary function and gas exchange abnormalities in morbid obesity. Int J Obes Relat Metab Disord (1995) 19(5):343-6.

48. Hedenstierna G, Santesson J, Norlander O. Airway closure and distribution of inspired gas in the extremely obese, breathing spontaneously and during anaesthesia with intermittent positive pressure ventilation. Acta Anaesthesiol Scand (1976) 20(4):334-42. doi:10.1111/j.1399-6576.1976.tb05036.x

49. Xu H, Barnes GT, Yang Q. Chronic inflammation in fat plays a crucial role in the development of obesity-related insulin resistance. J Clin Invest (2003) 112:1821-30. doi:10.1172/JCI19451

50. Wang CQ, Akalu YT, Suarez-Farinas M, Gonzalez J, Mitsui H, Lowes MA, et al. IL-17 and TNF synergistically modulate cytokine expression while suppressing melanogenesis: potential relevance to psoriasis. J Invest Dermatol (2013) 133(12):2741-52. doi:10.1038/jid.2013.237

Conflict of Interest Statement: The authors declare that the research was conducted in the absence of any commercial or financial relationships that could be construed as a potential conflict of interest.

Received: 16 June 2014; accepted: 30 August 2014; published online: 15 September 2014 Citation: Mathews JA, Wurmbrand AP, Ribeiro L, Neto FL and Shore SA (2014) Induction of IL-17A precedes development of airway hyperresponsiveness during dietinduced obesity and correlates with complement factor D. Front. Immunol. 5:440. doi: 10.3389/fimmu.2014.00440

This article was submitted to Inflammation, a section of the journal Frontiers in Immunology.

Copyright (c) 2014 Mathews, Wurmbrand, Ribeiro, Neto and Shore. This is an openaccess article distributed under the terms of the Creative Commons Attribution License (CC BY). The use, distribution or reproduction in other forums is permitted, provided the original author(s) or licensor are credited and that the original publication in this journal is cited, in accordance with accepted academic practice. No use, distribution or reproduction is permitted which does not comply with these terms. 